\title{
Sino-Nasal Outcome Test - 22 : Translation, Cross-cultural Adaptation, and Validation in Local Language
}

\author{
Aditya M Yeolekar, ${ }^{1}$ Vidya Rokade, ${ }^{1}$ Kiran Shinde, ${ }^{1}$ Netra Pathak, ${ }^{1}$ Haris Qadri, ${ }^{1}$ Kaustubh Kahane ${ }^{1}$
}

\section{Introduction:}

\section{ABSTRACT}

Quality of life questionnaires have been increasingly used in clinical studies to help estimate the magnitude of problem. SinoNasal Outcome Test-22 (SNOT-22) is considered to be a good tool to measure the severity of Sino-Nasal Diseases. As this test is in English, it may be difficult for the local population to express their symptoms correctly. Therefore we have translated and validated the SNOT- 22 test in local Indian language, Marathi.

Materials and Methods

An early Indian (Marathi) version of the SNOT 22 questionnaire was prepared. This was a prospective study, where forty patients with Sino-nasal Diseases confirmed on DNE \& CT(PNS) filled the questionnaire. This was repeated after a period of 14 days to retest. For validation the questionnaire was also filled by healthy individuals.

$\underline{\text { Results }}$

The mean SNOT-22 score $\pm S D$ was $50.17 \pm 18.65$ (range 10-93) in the initial test, and $49.61 \pm 18.40$ (range 21-91) in retest in the study group. Cronbach's alpha was 0.835 and 0.837 at the initial and retest examination respectively, both values were suggesting a good internal consistency. The mean SNOT-22 score $\pm S D$ was $13 \pm 11.68$ in the control group and $49.61 \pm 18.40$ (range 21-91) in the sino-nasal disease group and proved by Mann-Whitney U test.

Conclusion

The Marathi SNOT-22 is a valid instrument to assess the symptomatology of patients of Sino-nasal Diseases in Maharashtra. Kevwords:

Nose Diseases; Quality of Life; SNOT-22; Marathi

( uality of life questionnaires have been frequently employed in clinical studies in order to determine the severity of disease and the impact of medical or surgical intervention. ${ }^{1}$ Health status may be described by functional handicaps, physical limitations or the social experiences reported by the patients. According to this definition, physicians and other healthcare professionals may describe the health status of the patient only to some extent, but it is only the patient, individually, who can describe his/her own quality of life. ${ }^{2}$

Chronic Rhinosinusitis (CRS), which forms a major

1 - Smt Kashibai Navale Medical College and General Hospital.Pune

\section{Corresponding author:}

Dr Aditya M Yeolekar

email: adidoc@gmail.com chunk of Sino-Nasal Diseases is a multifactorial disease that affects the patients' health-related Quality Of Life (HRQOL). In terms of incidence as well as prevalence, CRS is comparable to heart disease and diabetes. ${ }^{3,4}$ Similar patterns of prevalence have been reported in Germany. ${ }^{4}$ The European position paper on rhinosinusitis and nasal polyps recommends the subjective assessment of symptoms using validated questionnaires. ${ }^{5}$

This has resulted in the development of a number of CRS specific assessment tools that are the following: SF36, RSOM-31,RSUI, RQLQ,SNOT-16,SN-5, SNOT11, SNOT-20, NOSE,CQ7. SNOT-20 and SNOT-22 are the two validated patient reported measures of the symptom severity and health related QOL in sinonasal conditions. ${ }^{2,6}$ SNOT-22 (2009) is a modified version of SNOT-20 and RSOM-31. SNOT-22 covers the physical problems, functional limitations as well as the emotional consequences of patients who suffer from 
CRS. ${ }^{7}$ The SNOT-22 scoring has already been adopted by many clinicians for the assessment of CRS and also for evaluating the outcome of the treatment of nasal polyposis ${ }^{8}$ and in surgery of nasal septum..${ }^{9}{ }^{10}$ Morley AD, Sharp HR et al. ${ }^{11}$ have analysed indices on reliability, validity and responsiveness and concluded that SNOT-22 can be applied as a tool for the QOL. Hopkins $\mathrm{C}$ et $\mathrm{al}^{12}$ have concluded that SNOT-22 can significantly discriminate between healthy and the diseased and further identified differences in subgroups of CRS. The author earlier studied SNOT-22 score in subjects not known to be suffering from rhino-sinusitis in India. ${ }^{13}$

Since this is a questionnaire in English, to use it in our country we need to translate it into a local language which could possibly eliminate the observer bias. Moreover, the meaning of quality of life and the ways through which health problems are expressed vary between the different cultures. ${ }^{1}$ Similar adaptations of SNOT 22 English version have been done elsewhere in the world i.e Denmark, ${ }^{4}$ Lithuinia, ${ }^{3}$ Brazil,${ }^{14}$ Persia, ${ }^{15}$ Hebrew, ${ }^{16}$ Moroccan, ${ }^{17}$ Spanish, ${ }^{18}$ French, ${ }^{19}$ and Chinese. ${ }^{20}$

The goal of the present study was to do the translation, cultural adaptation and validation of the SNOT-22 questionnaire from English into local Indian language of state of Maharashtra, Marathi, fourth most spoken language in India (about 73 million-2001 census). It is also ranks $19^{\text {th }}$ in the list of most spoken languages in the world. Therefore, the main purpose of the present study is to evaluate the modified version in Marathi of the SNOT-22 for its psychometric properties.

\section{Materials and Methods}

A prospective study was conducted on patients with Sino-nasal disease at SKN Medical College and General Hospital, Pune, Maharashtra, India. The study was accepted/approved by the hospital ethics committee. Validation of the Marathi questionnaire included translation of the original instrument from English to Marathi by two independent native Marathi language experts. A pilot study was undertaken among thirty medical students who knew both English and Marathi and were not known to be suffering from sino-nasal diseases. They were given original SNOT 22 in English and also our translated Marathi version of SNOT-22. The mean scores were comparable, 13 for SNOT 22 and 12 for Marathi version respectively. This proved the intelligibility of the questionnaire.

Inclusion criteria:

1) Patients diagnosed to be suffering from SinoNasal Diseases i.e. Deviated Nasal Septum, Chronic Rhinosinusitis, Sinonasal Polyp and confirmed on Diagnostic Nasal Endoscopy and CT- Paranasal Sinuses.

2) Those patients who could read and write Marathi.

Exclusion criteria were subjects below 18 years of age and acute infection at the time of presentation. Patients were informed about the nature and need of the study.

Missing data: Patients who were not available for retest examination and those who filled less than 50\% of test were excluded from the study.

Test-retest study: The test-retest reliability was carried out in patients with sino-nasal diseases, by employing SNOT-22 questionnaire twice during routine visits of the patient by two different physicians two weeks apart. Patients with change in treatment and with acute change of symptoms due to common cold/ influenza/ upper respiratory tract infection during the time period between completing the questionnaire were excluded from the study.

Control study: The Control group were recruited from healthy relative or attendant of patients, who were not known to be suffering from any sino-nasal diseases. Respondents were asked if they were, or had ever been diagnosed with sino-nasal disease or if they were using nasal medication and were excluded if they responded positively to any of the above. SNOT-22 (modified i.e. marathi) scores were obtained for the control group subjects.

The reliability of the tool was analyzed in following two ways: internal consistency as well as test and re-test reproducibility. Internal consistency has to do with the way with which each question is associated with others in the questionnaire which is measured by Cronbach's alpha coefficient. ${ }^{3}$ The value that is minimum acceptable is 0.7 . The test and retest reproducibility measures stability of an instrument along time after repetitive tests and is evaluated by the use of the questionnaire 
Table I: The Marathi translation of SNOT-22 questionnaire

\section{SINO-NASAL OUTCOME TEST - (SNOT) - 22 - MARATHI VERSION}

नाकाच्या आजारा मध्ये होणाय्या त्रासामुळे उद्भवणाय्या तक्रारी खाली नमूद केल्या आहेत. तक्रारी आणि होणारा त्रास यांचे एक कोष्ठक बनवले आहे.

तक्रारींचे स्वरुप आणि त्यामुळे होणारा त्रास ०ते ५ या पट्टीत आपल्याला सांगायचा आहे.

तरी आपणांस गेल्या दोन आठवड्यात होणाय्या त्रासानूसार खालील माहिती पर्ण करावी.

\begin{tabular}{|c|c|c|c|c|c|c|c|}
\hline किती त्रास होतो ते ० ते ५ या & & त्रास & ाचे प्रमा & ग ० ते । & या पट् & & \\
\hline तक्रारी & $\begin{array}{l}\text { त्रास } \\
\text { नाही }\end{array}$ & $\begin{array}{l}\text { क्वचित/ खूप } \\
\text { कमी त्रास }\end{array}$ & $\begin{array}{l}\text { थोडा/ } \\
\text { कमी }\end{array}$ & मध्यम & जास्त & $\begin{array}{l}\text { खूप जास्त/ } \\
\text { असहाय्य }\end{array}$ & $\begin{array}{l}\text { ५ प्रमुख } \\
\text { तक्रारी } \checkmark\end{array}$ \\
\hline १. शिंकरणे & 0 & १ & २ & ३ & $\gamma$ & 4 & \\
\hline २. शिंका येणे & $\circ$ & १ & २ & ३ & $\gamma$ & 4 & \\
\hline ३. नाकातून पाणी येणे & o. & १ & २ & ३ & $\gamma$ & 4 & \\
\hline ४. खोकला/ बेडका/ कफ & o & १ & २ & ३ & $\gamma$ & 4 & \\
\hline ५. घशात सर्दी येणे & $\circ$ & १ & २ & ३ & $\gamma$ & 4 & \\
\hline ६. जाड सर्दी / घट्ट सर्दी & 0 & q & २ & ३ & $\gamma$ & 4 & \\
\hline ७. कान बंद होणे/दडे बसणे & 0 & १ & २ & ३ & $\gamma$ & 4 & \\
\hline ८. चक्कर येणे & 0 & १ & २ & ३ & $\gamma$ & 4 & \\
\hline ९. कान दुखणे & $\sigma$ & १ & २ & ३ & $\gamma$ & 4 & \\
\hline १०. चेहरा दुखणे/जइपणा/ गच्च & $\circ$ & १ & २ & ३ & $\gamma$ & 4 & \\
\hline ११. झोप न येणे - & $\circ$ & १ & २ & ३ & $\gamma$ & 4 & \\
\hline १२. रात्रीत उठावे लागणे & $\overline{0}$ & १ & २ & ३ & $\gamma$ & 4 & \\
\hline १ ३. झोप पूर्ण न होणे & o. & $\xi$ & २ & ३ & $\gamma$ & 4 & \\
\hline १४. झोपेतून दमून उठणे & $\circ$ & f & २ & ३ & $\gamma$ & 4 & \\
\hline १५. दिवसा थकवा येणे & $\circ$ & १ & २ & ३ & $\gamma$ & 4 & \\
\hline १६. काम कमी होणे & $\circ$ & १ & २ & ३ & $\gamma$ & 4 & \\
\hline १७. लक्ष न लागणे & $\circ$ & १ & २ & ३ & $\gamma$ & 4 & \\
\hline १८. चिडचिड होणे & 0 & १ & २ & ३ & $\gamma$ & 4 & \\
\hline १९. उदास वाटणे & $\circ$ & $\uparrow$ & २ & ३ & $\gamma$ & 4 & \\
\hline २०. लाज वाटणे & 0 & १ & २ & ३ & $\gamma$ & 4 & \\
\hline २१. वास/चव न कळणे & o & $?$ & २ & ३ & $\gamma$ & 4 & \\
\hline २ २. नाक बंद होणे/ कोंडणे & $\overline{0}$ & १ & २ & ३ & $\gamma$ & 4 & \\
\hline एकूण & & & & & & & \\
\hline या शिवाय इतर काही तक्रार असल्य & & & & & & & \\
\hline
\end{tabular}


in different occasions, examining correlation among the scores. Pearson's test was used to compare test with retest scores in the Marathi SNOT-22 subscales.

The validity of the measures is the capacity the questionnaire has to reflect differences between known groups. The validity of the questionnaire was assessed using the Mann-Whitney test to compare Marathi SNOT scores between the control group and the Sino-Nasal disease group of the retest study. All statistical analyses were performed using SPSS statistical software. Values of $\mathrm{p}<0.05$ were considered as significant results.

\section{Result}

Translation: An early Indian (Marathi) version of the SNOT 22 questionnaire was prepared. (Table I)

Forty-six patients with Sino-nasal disease were recruited for the study. Two patients were not available for retest examination. On retest evaluation, two patients filled less than $50 \%$ of the questionnaire and two had an acute change of symptoms due to upper respiratory tract infection, thus they were excluded from the study. Test-retest reliability reflects stability over time with repeated testing. It is evaluated by correlating initial test and subsequent retest scores. ${ }^{4}$

Test-retest evaluation was finally accepted on 40 patients, 26 male (65\%) and 14 female (35\%). Mean time between test and retest evaluation was 8 days (range 6-10). The mean Marathi SNOT-22 score was $50.17 \pm 18.65$ (range 10-93) in the initial test, and $49.61 \pm 18.40$ (range 21-91) in retest. The minimum acceptable value for Cronbach's alpha test to represent and evaluate internal consistency for ordinal responses is $0.7 .3,{ }^{11}$ Cronbach's alpha was 0.835 and 0.837 at initial and retest examination respectively, both values suggesting good internal consistency within the Marathi SNOT-22 (homogenicity among different items).

Pearson's test (parametric correlation coefficient) in SNOT-22 has been evaluated by Schalek et all, ${ }^{21}$ Lange et $\mathrm{al}^{4}$ and Vaitkus et al. ${ }^{3}$ They have reported a Pearson's correlation coefficient of 0.86, 0.70 and 0.72 respectively. In our study, Pearson's correlation analysis was calculated for each item with a mean value of 0.99 , $(\mathrm{p}<0.001)$, suggesting reliability.

Control study: The control group consisted of 40 volunteers, 21 male $(52.5 \%)$ and 19 female $(47.5 \%)$. The mean SNOT-22 score \pm SD was $13 \pm 11.68$ in the control group and $49.61 \pm 18.40$ (range 21-91) in the sinonasal disease group. The difference was statistically significant $(\mathrm{p}<0.0001)$. (Table II)

The instrument was capable to differentiate the groups studied, demonstrating its validity. (Fig. 1) (Table III)

\section{Discussion}

There are over 15 known disease specific sinonasal outcome questionnaires in English. ${ }^{3}$ Among them, SNOT-22 questionnaire showed better internal consistency and responsiveness than other questionnaires and the SNOT-22 has already been validated in other languages worldover. ${ }^{3}$ This was the main reason for choosing SNOT-22 for validation in local language i.e. Marathi for patients of Maharashtra. This led to extraction of high quality data in patients own language which he/she can relate better. This Marathi SNOT-22 questionnaire proved to be reliable. The Marathi SNOT22 proved capable of differentiating groups of patients with sinonasal diseases from individuals without nasal

Table II: Total scores in two groups

\begin{tabular}{|c|c|c|c|}
\hline & MEAN \pm SD & RANGE & P-VALUE \\
\hline With Sino-nasal disease & $49.61 \pm 18.40$ & $21-91$ & $\mathbf{p}<0.0001)$ \\
\hline Healthy volunteers(control) & $13 \pm 11.68$ & $0-21$ & \\
\hline
\end{tabular}




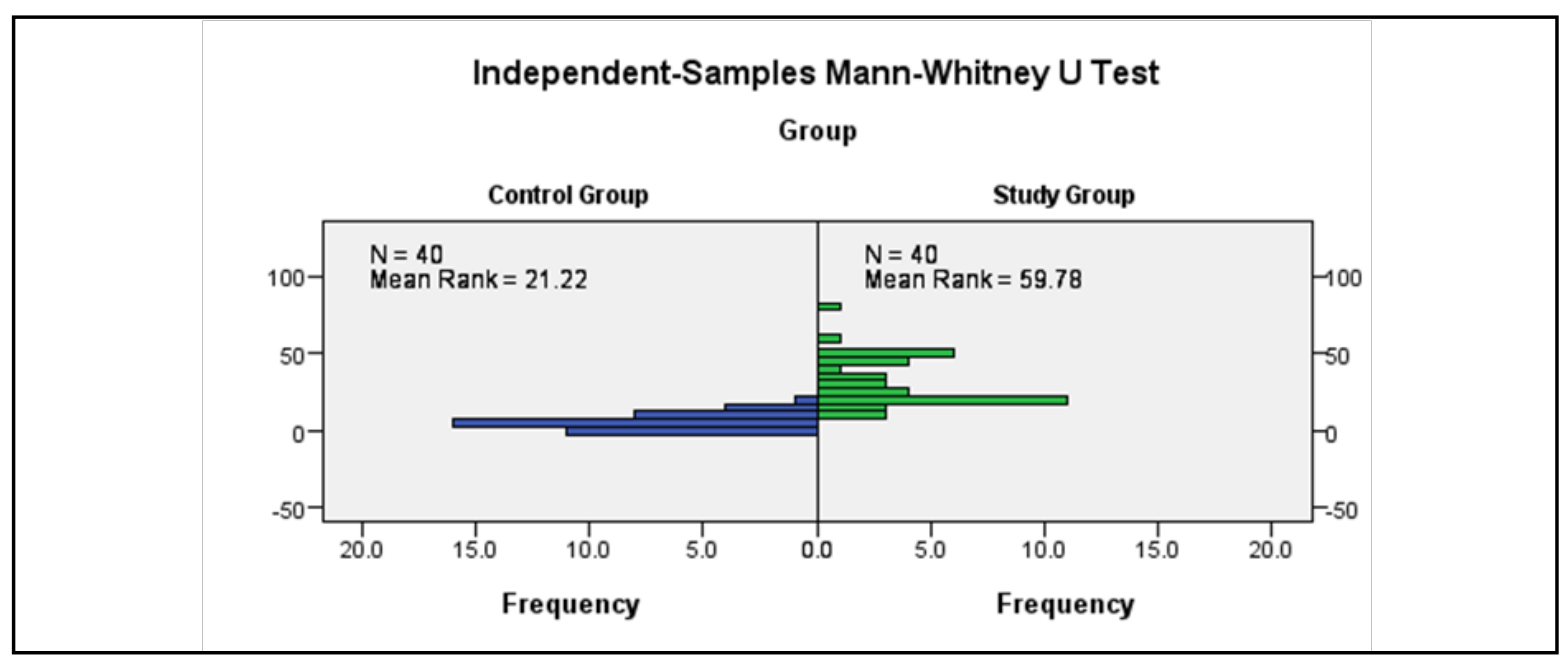

Fig. 1. Mann-Whitney U test

disease, hence the validity.

Our sample of healthy individuals (control) had a mean score of 13 points (marathi SNOT 22), close to the one presented by Hopkins et al. ${ }^{12}-9.3$ and the author 8.06., ${ }^{13}$ both using original SNOT-22. This points towards easy intelligibility and understanding of the questionnaire.

\section{Conclusion}

Our study demonstrates that the Marathi version of the SNOT-22 has good internal consistency, reliability and validity. It is a valid instrument for assessing quality of life (QOL) of patients of Sino-nasal diseases in Maharasthra. It is a very simple tool to use as it is in local language for the patient, nursing staff, health attendant and doctor alike. It can be put to use at all levels of health care intervention, primary ,secondary and tertiary to detect the severity of sino-nasal disease of the patient. It could also be used as an instrument for audit. It could further be used to determine the effectiveness of medical or surgical intervention in sinonasal diseases. Similarly, translation of other quality of life health questionnaires could be employed to extract quality data in local Indian languages.

\section{Acknowledgments}

The author thanks DrA V Bhore, Director and Dr Bangal, Dean for support and to all patients for participation.

\section{Ethical approval}

All procedures performed in studies involving human participants were in accordance with the ethical standards of the institutional and/or national research committee and with the 1964 Helsinki declaration and its later amendments or comparable ethical standards.

Table III: Mann-Whitney U Test (p value $<0.05$ to be considered significant)

\begin{tabular}{|c|c|c|c|}
\hline & MANN - WHITNEY U TEST & P VALUE & RESULT \\
\cline { 1 - 3 } Study Group (Initial Value) & \multirow{2}{*}{29.00} & $\mathbf{0 . 0 0 0}$ & Significant \\
\hline Control Group & & & \\
\hline
\end{tabular}




\section{Informed consen}

Informed consent was obtained from all individual participants included in the study.

\section{References}

1. Guillemin F, Bombardier C, Beaton D. Cross-cultural adaptation of health-related quality of life measures: literature review and proposed guidelines. J Clin Epidemiol. 1993; 46(12):1417-32

2. Picirillo JF, Merritt MG, Richards ML. Psychometric and clinimetric validity of the 20-item Sino-Nasal Outcome Test (SNOT-20). Otolar-yngol Head Neck Surg. 2002; 126(1):41-7

3. Vaitkus S, Padervinskis E, Balsevicius T, Siupsinskiene N, Staikuniene J, Ryskiene S, Lisauskaite L, Vaitkus J. Translation, cross-cultural adaptation, and validation of the sino-nasal outcome test (SNOT)-22 for Lithuanian patients. Eur Arch Otorhinolaryngol. 2013; 270(6): 1843-8 doi: 10.1007/s00405012-2282-2

4. Lange B, Thilsing T, Al-kalemji A, Baelum J, Martinussen T, Kjeldsen A (2011) The Sino-Nasal Outcome Test 22 validated for Danish patients. Dan Med Bull. 2011; 58(2): A4235

5. Fokkens W, Lund V, Mullol J. European position paper on rhinosinusitis and nasal polyps. Rhinol Suppl. 2007; 20:1-136

6. Anderson ER, Murphy MP, Weymuller EA, Jr. Clinimtric evaluation of the Sinonasal Outcome Test-16. Student Research Award 1998. Otolaryngol Head Neck Surg. 1999;121:702-7 http://dx.doi.org/10.1053/hn.1999.v121.a100114

7. Browne JP, Hopkins C, Slack R, et al. The Sino-Nasal Outcome Test (SNOT): can we make it more clinically meaningful? Otolaryngol Head Neck Surg. 2007; 136: 736-41. http://dx.doi. org/10.1016/j.otohns.2007.01.024

8. Browne JP, Hopkins C, Slack R, et al. Health-related quality of life after polypectomy with and without additional surgery. Laryngoscope 2006; 116: 297-302. http://dx.doi. org/10.1097/01.mlg.0000198338.05826.18

9. Buckland JR, Thomas S, Harries PG. Can the Sino-nasal Outcome Test (SNOT-22) be used as a reliable outcome measure for successful septal surgery? Clin Otolaryngol Allied Sci. 2003; 28: 43-7 http://dx.doi.org/10.1046/j.13652273.2003.00663.x

10. Pannu KK, Snya Chadha S, Kaur IP. Evaluation of benefits of nasal septal surgery on nasal symptoms and general health.
Indian J Otolaryngol Head Neck Surg 2009; 61(1): 59-65 http:// dx.doi.org/10.1007/s12070-009-0036-2.

11. Morley AD, Sharp HR. A review of sinonasal outcome scoring systems - which is best? Clin Otolaryngol. 2006; 31(2): 103-9

12. Hopkins C, Gillett S, Slack R, Lund VJ, Browne JP. Psychometric validity of the 22-item Sinonasal Outcome Test. Clin Otolaryngol. 2009; 34(5): 447-54 http://dx.doi. org/10.1111/j.1749-4486.2009.01995.x

13. Yeolekar Aditya M, Dasgupta K S et al. A Study of SNOT 22 Scores in Adults with no Sinonasal Disease. Journal of Rhinolaryngo-Otologies 2013; 1:6-10

14. Kosugi E M, Vitor Guo Chen et al. Translation, cross-cultural adaptation and validation of SinoNasal Outcome Test (SNOT) - 22 to Brazilian Portuguese. Braz J Otorhinolaryngol. 2011; 77(5):663-9

15. Maryam Jalessi, Mohammad Farhadi et al. The Reliability and Validity of the Persian Version of Sinonasal Outcome Test 22 (Snot 22) Questionnaires. Iran Red Crescent Med J. 2013 15(5): 404-8 doi: 10.5812/ircmj.7937 .PMCID: PMC3838650

16. Shapira Galitz Y, Halperin D et al. Sino-Nasal Outcome Test22: Translation, Cross-cultural Adaptation, and Validation in Hebrew-Speaking Patients.Otolaryngol Head Neck Surg. 2016; 154(5):951-6 doi: 10.1177/0194599816629378

17. Adnane $\mathrm{C}$, Adouly $\mathrm{T}$ et al. Psychometric Validation of a Moroccan Version of the 22-Item Sino-Nasal Outcome Test. Otolaryngol Head Neck Surg. 2016; 155(4):681-7 doi: 10.1177/0194599816650477

18. de los Santos G, Reyes P et al. Cross-cultural adaptation and validation of the sino-nasal outcome test (SNOT-22) for Spanish-speaking patients.Eur Arch Otorhinolaryngol. 2015; 272(11):3335-40 doi: 10.1007/s00405-014-3437-0

19. de Dorlodot $\mathrm{C}$, Horoi $\mathrm{M}$ et al. French adaptation and validation of the sino-nasal outcome test-22: a prospective cohort study on quality of life among 422 subjects.Clin Otolaryngol. 2015; 40(1):29-35 doi: 10.1111/coa.12315

20. Lü W, Qi F et al. Quality of life survey on patients with chronic rhinosinusitis by using Chinese version of the 22 -item sinonasal outcome test (SNOT-22). Zhonghua Er Bi Yan Hou Tou Jing Wai Ke Za Zhi 2008; 43(1):18-21

21. Schalek P, Otruba L, Hahn A. Quality of life in patients with chronic rhinosinusitis: a validation of the Czech version of SNOT-22 questionnaire. Eur Arch Otorhinolaryngol. 2010; 267(3):473-475. 